\title{
Human and Rodent Skeletal Muscles Express Angiotensin II Type 1 Receptors
}

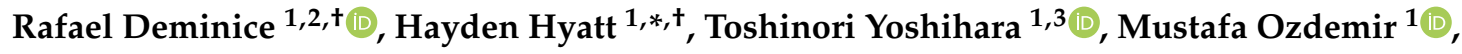 \\ Branden Nguyen ${ }^{1}$, Sanford Levine ${ }^{4}$ and Scott Powers ${ }^{1}$ \\ 1 Department of Applied Physiology and Kinesiology, University of Florida, Gainesville, FL 32608 USA; \\ rdeminice@uel.br (R.D.); t-yoshih@juntendo.ac.jp (T.Y.); ozdemirm@ufl.edu (M.O.); \\ branden.nguyen@ufl.edu (B.N.); spowers@hhp.ufl.edu (S.P.) \\ 2 Department of Physical Education, State University of Londrina, Londrina 860570-970, Brazil \\ 3 Department of Exercise Physiology, Juntendo University, Chiba 270-1695, Japan \\ 4 Department of Surgery, University of Pennsylvania, Philadelphia, PA 19104, USA; \\ sdlevine@mail.med.upenn.edu \\ * Correspondence: haydenhyatt@ufl.edu; Tel.: +1-352-294-1713; Fax: +1-352-392-0316 \\ + These authors have contributed equally to this work.
}

Received: 10 June 2020; Accepted: 9 July 2020; Published: 14 July 2020

Abstract: Abundant evidence reveals that activation of the renin-angiotensin system promotes skeletal muscle atrophy in several conditions including congestive heart failure, chronic kidney disease, and prolonged mechanical ventilation. However, controversy exists about whether circulating angiotensin II (AngII) promotes skeletal muscle atrophy by direct or indirect effects; the centerpiece of this debate is the issue of whether skeletal muscle fibers express AngII type 1 receptors (AT1Rs). While some investigators assert that skeletal muscle expresses AT1Rs, others argue that skeletal muscle fibers do not contain AT1Rs. These discordant findings in the literature are likely the result of study design flaws and additional research using a rigorous experimental approach is required to resolve this issue. We tested the hypothesis that AT1Rs are expressed in both human and rat skeletal muscle fibers. Our premise was tested using a rigorous, multi-technique experimental design. First, we established both the location and abundance of AT1Rs on human and rat skeletal muscle fibers by means of an AngII ligand-binding assay. Second, using a new and highly selective AT1R antibody, we carried out Western blotting and determined the abundance of AT1R protein within isolated single muscle fibers from humans and rats. Finally, we confirmed the presence of AT1R mRNA in isolated single muscle fibers from rats. Our results support the hypothesis that AT1Rs are present in both human and rat skeletal muscle fibers. Moreover, our experiments provide the first evidence that AT1Rs are more abundant in fast, type II muscle fibers as compared with slow, type I fibers. Together, these discoveries provide the foundation for an improved understanding of the mechanism(s) responsible for AngII-induced skeletal muscle atrophy.

Keywords: renin angiotensin system; muscle atrophy; mechanical ventilation; diaphragm; muscle wasting

\section{Introduction}

The renin-angiotensin system (RAS) is well known for its role in the regulation of blood pressure, fluid homeostasis, and electrolyte balance. Importantly, compelling evidence reveals that increased RAS signaling promotes skeletal muscle atrophy (reviewed in [1-4]). Indeed, congestive heart failure, chronic kidney disease, and prolonged bed rest are all conditions associated with skeletal muscle atrophy resulting from elevated circulating angiotensin II (AngII) [5-9].

In theory, high plasma levels of AngII can promote skeletal muscle atrophy by indirect or direct effects on skeletal muscle fibers. For example, AngII can indirectly foster muscle atrophy by increasing 
circulating glucocorticoids (i.e., cortisol), interleukin-6 (IL-6), or serum amyloid A (SAA). Indeed, elevated plasma levels of cortisol, IL-6, or SAA can independently, or collectively, stimulate skeletal muscle atrophy [10]. In particular, elevated cortisol promotes muscle atrophy by increasing proteolysis and decreasing muscle protein synthesis [11]. Furthermore, high concentrations of IL-6 and SAA act synergistically to evoke muscle atrophy by depressing Akt/mTOR signaling resulting in decreased muscle protein synthesis and accelerated proteolysis [10].

In addition to these indirect actions, high circulating AngII can directly stimulate muscle atrophy by binding to angiotensin II type I receptors (AT1Rs) on the sarcolemma of muscle fibers. This direct stimulation of AT1R signaling in muscle fibers activates the predominant NADPH oxidase isoform (NADPH oxidase 2, NOX2) in skeletal muscle culminating in superoxide production, increased proteolysis, and fiber atrophy $[3,12]$.

Although it is feasible that circulating AngII can act directly to promote skeletal muscle atrophy, controversy exists about whether skeletal muscle fibers express AT1Rs. For example, one camp of investigators contend that skeletal muscle does not express AT1Rs and that AngII promotes fiber atrophy by indirect effects alone $[4,10,13]$. In contrast, other investigators argue that skeletal muscle fibers express AT1Rs and that AngII stimulates muscle atrophy by directly binding to AT1Rs on the sarcolemma [14-19]. These discordant findings are likely the result of limitations in previous studies. For example, most reports have used commercially available antibodies that exhibited nonspecific binding $[20,21]$. Furthermore, several studies have reported the abundance of AT1Rs within whole muscle homogenate that is contaminated with other tissues that express AT1Rs (e.g., blood vessels). Moreover, several investigations have measured AT1R abundance in myotubes that did not reflect the number of AT1Rs within adult skeletal muscle fibers. Hence, experiments that avoid these shortcomings are required to establish if AT1Rs are expressed in adult skeletal muscle fibers. Therefore, using a rigorous experimental approach, we tested the hypothesis that AT1Rs are expressed in both human and rat skeletal muscles. This postulate was carefully tested using a multi-technique approach. First, we established both the location and abundance of AT1Rs on skeletal muscle fibers using an AngII ligand-binding assay. Second, using a new and highly selective AT1R antibody, we carried out Western blotting to determine the abundance of AT1R protein within isolated single muscle fibers. Finally, we confirmed the presence of AT1R mRNA in isolated single muscle fibers from rodents. Collectively, our results reveal that AT1Rs are present in both human and rodent skeletal muscle and that AT1Rs are differentially expressed across different rodent skeletal muscle fiber types.

\section{Materials and Methods}

\subsection{Institutional Approval for Experiments}

The protocol for human muscle biopsies was approved by the University of Pennsylvania institutional review board (IRB protocol ID: 802015, 2007). All biopsy specimens were obtained with appropriate written informed consent. All animal experimental procedures were performed in accordance with the Institute of Animal Care and Use Committee at the University of Florida (IACUC protocol ID: 201810432, 2018).

\subsection{Human Diaphragm Biopsies}

Human diaphragm muscle biopsies were obtained from 6 patients ( 3 female, 3 male, ages 18-58) undergoing surgery for either benign lesions or stage 1 lung cancer. Full-thickness biopsy specimens were removed from the right anterior costal diaphragm. Muscle samples were rapidly frozen in isopentane, cooled to the temperature of liquid nitrogen, and stored at $-80{ }^{\circ} \mathrm{C}$ until assay.

\subsection{Animal Muscle Dissections}

Female Sprague-Dawley rats ( 4 months old, $n=9)$ were used in this study. Animals were housed at the University of Florida Animal Care Service Center and maintained at a 12:12 h light-dark cycle at 
a mean temperature of $22{ }^{\circ} \mathrm{C}$ with ad libitum access to food and water. Following animal sacrifice, the descending aorta, kidneys, diaphragm, soleus, and plantaris muscles were dissected. Tissues were immediately frozen in isopentane, cooled to the temperature of liquid nitrogen, and stored at $-80{ }^{\circ} \mathrm{C}$ for subsequent analysis.

\subsection{Experimental Approach}

To test the hypothesis that skeletal muscle fibers express AT1Rs, we studied both respiratory and locomotor skeletal muscles and used a multi-technique approach. For example, to determine if skeletal muscle express AT1Rs, we isolated individual muscle fibers from both the human diaphragm and three skeletal muscles in the rat (i.e., diaphragm, soleus, and plantaris). The diaphragm was selected for analysis in both humans and rodents because of recent reports demonstrating that RAS signaling plays a key role in ventilator-induced diaphragm atrophy [22,23]. No gender differences exist in the rate or patterns of skeletal muscle atrophy during hindlimb immobilization or the diaphragmatic atrophy that occurs during prolonged mechanical ventilation. Therefore, female rats were arbitrarily selected for study in these experiments. The rat soleus and plantaris muscles were studied because these rodent hindlimb locomotor muscles atrophy in response to atrophic stimuli and these muscles differ markedly in their fiber type composition; the soleus muscle in rats contains primarily slow, type I fibers, whereas the plantaris muscle is dominated by fast, type II fibers [24]. The rat aorta and kidneys were examined for comparative purposes because these tissues are known to contain large numbers of AT1Rs.

To determine the presence of AT1Rs in muscle fibers, we used a three-pronged experimental approach as follows: (1) Immunoblotting, using a highly selective antibody, to determine the presence of AT1Rs in single muscle fibers; (2) identification of AT1Rs on the sarcolemma of skeletal muscle fibers using an AngII binding assay; and (3) determination of AT1R mRNA in isolated single muscle fibers from rats. Details of these experimental procedures follow.

\subsection{Immunoblotting}

The relative abundance of AT1R protein was determined via Western blot analysis using homogenate from isolated single muscle fibers of human diaphragm and the diaphragm, soleus, and plantaris muscles from rats. Single muscle fiber isolation was performed to eliminate contamination of the homogenate with AT1R protein contained within other tissues (e.g., vasculature) found in bundles of muscle fibers. Specifically, $\sim 100$ single muscle fibers ( $\sim 3 \mathrm{~mm}$ long) were isolated under a stereomicroscope (AO569, American Optical, Southbridge, MA, USA) in a (relax) solution containing $100 \mathrm{mM} \mathrm{KCl}, 20 \mathrm{mM}$ imidazole, 4 mM ATP, 2 mM EGTA, and $7 \mathrm{mM} \mathrm{MgCl} 2$ (pH 7.0 adjusted with KOH); isolated fiber were placed into an Eppendorf tube containing Tris-EDTA buffer ( $5 \mathrm{mM}$ Tris, $5 \mathrm{mM}$ EDTA, and $1 \%$ Triton $\mathrm{X}-100, \mathrm{pH} 7.4$ ) and 1:20 vol/vol protease inhibitor cocktail (Sigma-Aldrich, St. Louis, MO, USA). Samples were, then, exposed to 3 freeze/thaw cycles and homogenized with a small pestle. Then, samples were centrifuged at $1500 \times g$ for $10 \mathrm{~min}$ and the supernatant was placed in Laemmli sample buffer (Bio Rad, 1610747, Hercules, CA, USA) containing 5\% dithiothreitol. The muscle fiber homogenates were, then, boiled for $5 \mathrm{~min}$. Proteins within the homogenate were separated via polyacrylamide gel electrophoresis, transferred onto a PVDF membrane, and incubated with an AT1R antibody that had recently been validated with both knockout and overexpression animals [25]. The AT1R antibody was a gift of Dr. Kate Murphy (University of Melbourne, Melbourne, Australia). Membranes were incubated with Alexa Fluro 800 IgG secondary, scanned, and analyzed using an infrared imager (LI-COR Bioscience, Lincoln, NE, USA) using Odyssey 2.1 software. All Western blot images were normalized to total protein using REVERT total protein stain (LI-COR Bioscience). Importantly, REVERT total protein staining has been demonstrated to be superior for Western blot normalization as compared with the use of housekeeping proteins [26]. Note that anti-CD31 (Abcam, \#ab28364), a biomarker of vascular tissue, was used to ensure that single muscle fiber samples were not contaminated with vascular tissue. Additionally, PAX7 (Developmental Studies Hybridoma 
Bank, \#AB 528428) was used to determine the abundance of satellite cells within the single muscle fiber homogenate.

\subsection{Identification of AT1R Using a Fluorescence-Based Binding Assay}

A fluorescence-based binding assay for AT1R was performed using methods adapted from $[27,28]$. Briefly, AngII was conjugated to the fluorophore TAMRA 5(6)-carboxytetramethylrodamine. OCT-embedded vasculature, kidney, diaphragm, soleus, and plantaris muscles were frozen and serially cut in a cryostat (HM550 Cryostat, Thermo Fisher Scientific, Waltham, MA, USA) in $10 \mu \mathrm{m}$ sections; then, tissue sections were mounted on slides and dried for $1 \mathrm{~h}$, at $4{ }^{\circ} \mathrm{C}$. The sections were, then, preincubated in assay buffer composed of Hanks' Balanced Salt solution (Thermo Fisher Scientific, \#14025076) supplemented with $0.2 \%$ bovine serum albumin (BSA), $0.01 \%$ bacitracin, $0.002 \%$ phenylmethylsulfonyl fluoride (PMSF), and 0.01\% 1,10-phenanthroline, for $30 \mathrm{~min}$, in an ice bath. Slides were, then, air-dried for $5 \mathrm{~min}$ and incubated with the following conditions: (1) assay buffer containing unlabeled AngII (Sigma-Aldrich, A9525, St. Louis, MO), (2) assay buffer containing $5 \mu \mathrm{M}$ TAMRA-labeled AngII peptide (AnaSpec, Fremont, Ca, AS-61181), (3) assay buffer containing unlabeled AngII with Losartan, and (4) assay buffer containing TAMRA-labeled AngII with losartan. Slides were incubated in their respective buffer, for $1 \mathrm{~h}$, on ice. Following incubation, sections were quickly rinsed three times with assay buffer, and then washed five times in assay buffer, for 1 min each. Slides were dried and fluorescence was measured on an Axiovert 200 fluorescent microscope (Zeiss, Göttingen, Germany) using a rhodamine excitation fluorescence filter. For AT1R quantification, the auto local thresholding technique [29] was used to quantify relative fluorescence density in the AT1R binding sections using ImageJ software (National Institutes of Health, Rockville, MD, USA). Relative AT1R values were generated by subtracting background fluorescence (the value of threshold fluorescence detected in the presence of losartan and co-incubated with TAMRA-AngII from serially sectioned tissues from the same sample) from total threshold fluorescence (fluorescence detected with TAMRA-AngII without losartan). All measurements were made in triplicate. Sections incubated in AngII without the TAMRA label were used as negative controls.

Proof-of-concept for this technique was confirmed during preliminary experiments corroborating the existence of AT1Rs in skeletal muscle as compared with other tissues known to express high levels of AT1Rs. Moreover, the concentration of losartan required for maximal blockade of AT1Rs was also determined during pilot studies (see Supplementary Materials, Figure S1).

Finally, a non-quantitative fluorescent-based binding assay for AT1R was also performed using isolated single fibers of diaphragm, soleus, and plantaris muscles. The objective of this procedure was to confirm that AT1Rs exist on the sarcolemma of muscle fibers. Single muscle fibers were isolated under a stereomicroscope in a relax solution and placed on a microscope slide. The single fibers were, then, cut into three segments ( $2 \mathrm{~mm}$ long) and each section was incubated in one of the following three different solutions: (1) assay buffer containing unlabeled AngII, (2) assay buffer containing $5 \mu \mathrm{M}$ TAMRA-labeled AngII peptide, or (3) assay buffer containing TAMRA-labeled AngII with 1 $\mathrm{mM}$ losartan. Solution preparation, incubation, and wash procedures were the same as described previously for tissue sections.

\subsection{AT1R $m R N A$}

Because of limited tissue availability of the human diaphragm samples, AT1R mRNA levels were measured in rat skeletal muscles only. To determine the AT1R (Agtr1a) mRNA levels in single fibers from plantaris, soleus, and diaphragm muscles, bundles of muscle fibers were placed in RNAlater-ICE for overnight, at $-20^{\circ} \mathrm{C}$. The fiber bundles were, then, washed in RNAlater and placed in relax buffer (100 mM KCl, $20 \mathrm{mM}$ imidazole, 2 mM EGTA, $4 \mathrm{mM}$ ATP, $7 \mathrm{mM} \mathrm{MgCl} 2$, pH 7.0) on ice. Then, the muscle fibers were isolated from the muscle bundle using fine tweezers under a stereomicroscope (AO569, American Optical). The fibers were freed of connective tissue, vascular, and other debris and $\sim 100$ fibers $(\sim 3 \mathrm{~mm}$ length) were quickly placed into $10 \mu \mathrm{L}$ of TRIZOL Reagent (Invitrogen, 
Carlsbad, CA, USA). Immediately after single-fiber isolation, $140 \mu \mathrm{L}$ TRIZOL Reagent was added (150 $\mu \mathrm{L}$ total solution), the fibers were homogenized using a homogenizer pestle, and then stored at $-80^{\circ} \mathrm{C}$ until analysis. After $5 \mathrm{~min}$ incubation at room temperature, $30 \mu \mathrm{L}$ of 1-bromo-3-chloropropane was added and tubes were vortexed and incubated for $3 \mathrm{~min}$ at room temperature. The mixture was, then, centrifuged at $13,000 \times g$ for $15 \min \left(4^{\circ} \mathrm{C}\right)$ and the supernatant collected. For RNA precipitation, $2 \mu \mathrm{L}$ of glycogen (Thermo Fisher Scientific, Waltham, MA, USA) was added to the supernatant and mixed with $100 \mu \mathrm{L}$ of isopropanol, incubated at room temperature for $10 \mathrm{~min}$, and at $4{ }^{\circ} \mathrm{C}$ for $30 \mathrm{~min}$, and then centrifuged at $13,000 \times g$ for $45 \mathrm{~min}$. The supernatant was, then, removed, $0.5 \mathrm{~mL}$ of ice-cold $75 \%$ ethanol was added, and the mixture centrifuged at $13,000 \times g$ for $10 \mathrm{~min}$. Pellet wash and centrifugation were repeated once again using $70 \%$ ethanol before pellet was dried in air and dissolved in $10 \mu \mathrm{L}$ of RNase-free water. The concentration and purity (A260/280 and A260/230) of total RNA were determined using a NanoDrop (Thermo Fisher Scientific, ND-2000, Waltham, MA, USA) and reverse transcription was performed with an input of $2.5 \mu \mathrm{g}$ total RNA using SuperScript VILO MasterMix (Invitrogen).

The PCR conditions used were as follows: $50^{\circ} \mathrm{C}$ for $10 \mathrm{~min}$, then 40 cycles at $95^{\circ} \mathrm{C}$ for $15 \mathrm{~s}$ and $60^{\circ} \mathrm{C}$ for $1 \mathrm{~min}$, with a final cycle at $37^{\circ} \mathrm{C}$ for $30 \mathrm{~s}$, in a StepOne Plus Real-Time PCR System (Thermo Fischer Scientific). Agtr1a (Rn01435427_m1) mRNA levels were quantified using a TaqMan gene expression assay (Thermo Fischer Scientific) and were normalized to ACTB (Rn00667869_m1) mRNA levels. Measurements were done in duplicate and the $2^{-\Delta \Delta C t}$ method was used for data analysis (cycle threshold $(\mathrm{Ct})=\mathrm{Ct}$ (gene of interest) $-\mathrm{Ct}$ (reference gene)). Relative changes $(\Delta \Delta \mathrm{Ct})$ in the expression level of target gene were calculated by subtracting the $\Delta \mathrm{Ct}$ of the diaphragm muscle.

\subsection{Statistical Analysis}

Data are presented as mean \pm standard deviation. Comparisons between groups were made by one-way ANOVA, and when appropriate, a Tukey post-hoc test was performed. Significance was established at $p<0.05$.

\section{Results}

\subsection{AT1R Abundance in Rat Skeletal Muscles Determined by AngII-Binding Assay}

Our experiments tested the hypothesis that human and rat skeletal muscles express AT1Rs. In this regard, note that humans express only one AT1R isoform, whereas rats express two isoforms (labeled as $A T 1 R_{A}$ and $A T 1 R_{B}$ ) [21]; the two $A T 1 R$ isoforms in rats share $94 \%$ identity and are indistinguishable pharmacologically [21]. To determine the abundance of AT1Rs in rat skeletal muscles, we employed three complimentary approaches. First, we utilized a fluorescent-ligand binding assay (TAMRA-labeled AngII) to determine both the location and abundance of AT1Rs in skeletal muscles. Our results reveal that AT1Rs exist in the diaphragm, soleus, and plantaris muscles, as evidenced by a well-defined fluorescence label along the sarcolemma of muscle fibers which agrees with the known location of AT1Rs (Figure 1A (a-c)). In addition, notice that the intensity of the fluorescence was markedly diminished when muscle sections were incubated with losartan to prevent binding of AngII to AT1Rs (Figure 1A (d-f)); this confirms that the fluorescence signal in the muscle was dominated by TAMRA-labeled AngII binding to an $\mathrm{AT}_{1} \mathrm{R}_{\mathrm{A}}$ or $\mathrm{AT} \mathrm{R}_{\mathrm{B}}$. 
A)
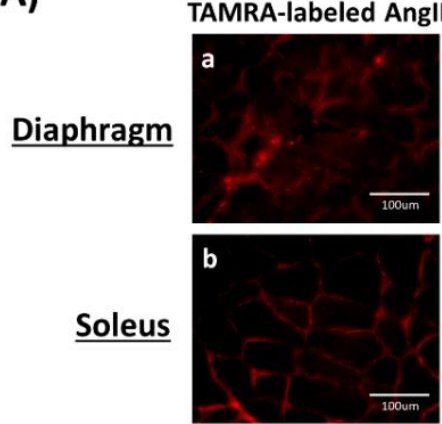

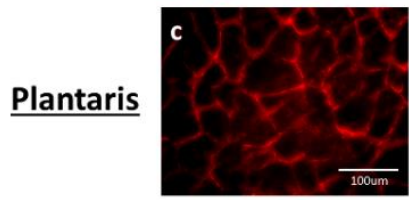

TAMRA-labeled Angll + Losartan

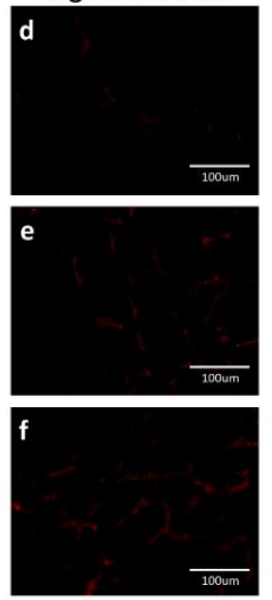

B)

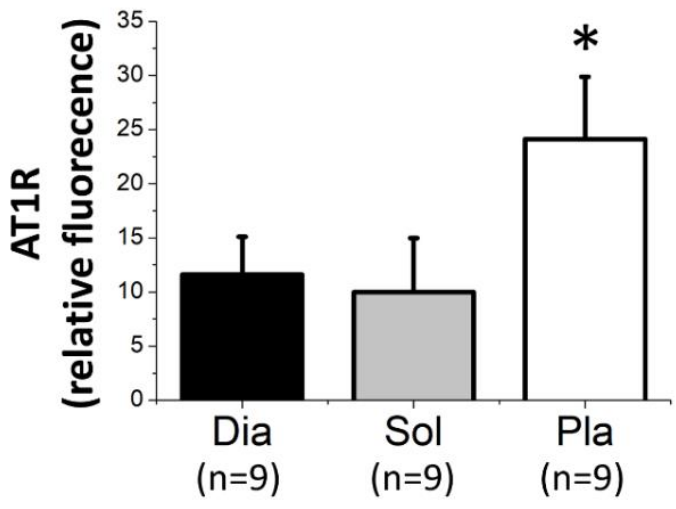

Figure 1. Angiotensin II (AngII) ligand-binding assay reveals the presence and abundance of AT1Rs on the sarcolemma of three rat skeletal muscles. Panel (A) contains photographs of TAMRA-labeled AngII binding in muscle cross sections of the diaphragm, soleus, and plantaris muscle. Images a-c represent total AngII binding in each muscle and images $\mathrm{d}-\mathrm{f}$ depict the nonspecific binding in the presence of losartan; AT1R quantification (Panel (B), histogram) was performed by subtracting relative fluorescence of TAMRA-labeled AngII in the presence of losartan (nonspecific binding) from total binding. Data are mean \pm SD. ${ }^{*}$ different $(p<0.05)$ from diaphragm (Dia) and from soleus (Sol).

Next, to determine if differences exist in the abundance of AT1Rs between muscles that differ in fiber type composition, we compared the fluorescence levels between cross sections of the diaphragm, soleus, and plantaris muscles. A comparison of the relative fluorescence between these three muscles reveals a higher abundance of AT1Rs within the plantaris muscle as compared with both the soleus and diaphragm muscle (Figure 1B). This is a new and important finding indicating that AT1R abundance is greater in skeletal muscles that contain a high percentage of fast fibers (i.e., plantaris) as compared with muscles comprised of slow fibers (i.e., soleus) or muscles containing a mixture of both slow and fast fibers (i.e., diaphragm).

Finally, to confirm that the fluorescent signal of AngII ligand binding in the muscle cross sections was not due to AT1Rs in the vasculature, isolated single muscle fibers were also incubated with TAMRA-labeled AngII; these images clearly illustrate the presence of AT1Rs on the sarcolemma of single muscle fibers from the diaphragm, soleus, and plantaris muscles (Figure $2 \mathrm{~d}-\mathrm{f}$ ). Note that the fluorescent intensity was absent when single muscle fibers were incubated with non-fluorescent AngII (Figure 2a-c). Importantly, the ligand binding of fluorescent AngII was inhibited by blockade of AT1Rs via losartan (Figure 2g-i). 


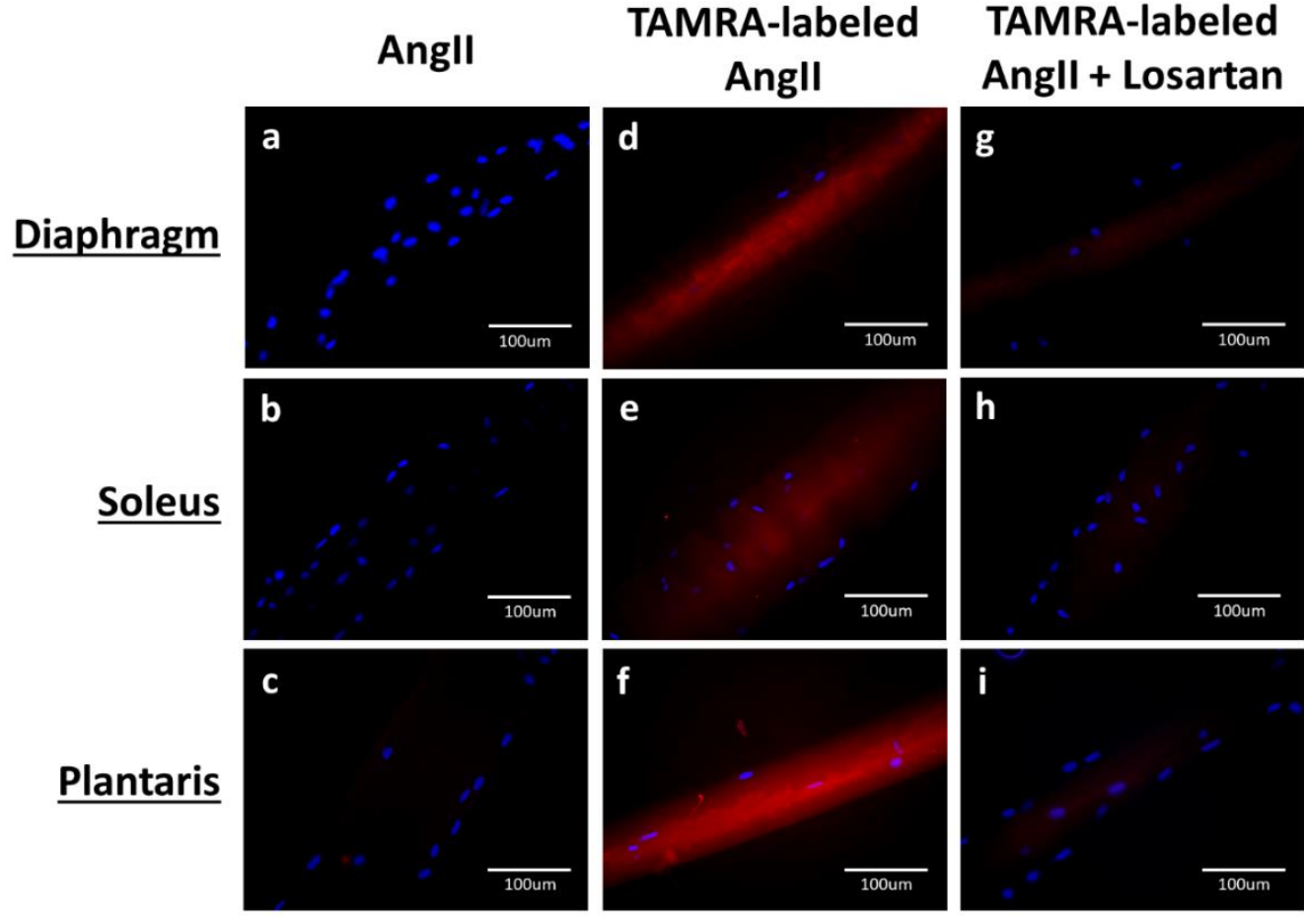

Figure 2. Single fiber histology confirms sarcolemma localization of AT1R in rat skeletal muscles. Figures demonstrate isolated muscle fibers incubated with non-labeled Ang II (a-c); total binding after incubation with TAMRA-labeled AngII (d-f); and nonspecific binding after incubation with TAMRA-labeled AngII + 1 mM losartan (g-i). Skeletal muscle nuclei are identified in blue (DAPI).

\subsection{Western Blotting to Determine AT1R Abundance in Rat Skeletal Muscles}

To provide a second approach to the question of whether AT1Rs are expressed in skeletal muscle, we utilized a recently validated AT1R antibody and performed Western blots on protein homogenates from isolated single muscle fibers [25]. These results corroborate the presence of AT1Rs in skeletal muscle fibers and provide additional support for the hypothesis that skeletal muscles express AT1Rs. To verify that our single fiber homogenates were not contaminated with vascular tissue, we also performed Western blots to determine the presence of the vascular biomarker, CD31. Importantly, CD31 was undetectable in the isolated muscle fiber homogenate (data not shown). Finally, because AT1Rs are present in satellite cells [30], we also assayed the single fiber homogenate for evidence of the satellite cell biomarker, PAX7; notably, PAX7 was not detectable in these homogenates (data not shown).

Lastly, our Western blot results also support our findings with the fluorescent AngII-binding assay data indicating that the relative abundance of AT1Rs is greatest in the fast plantaris muscle as compared with muscles comprised of slow, type I muscle fibers (soleus) or muscles containing a mixture of slow and fast fiber types (diaphragm) (Figure 3). 


\section{Rodent Muscle AT1R}
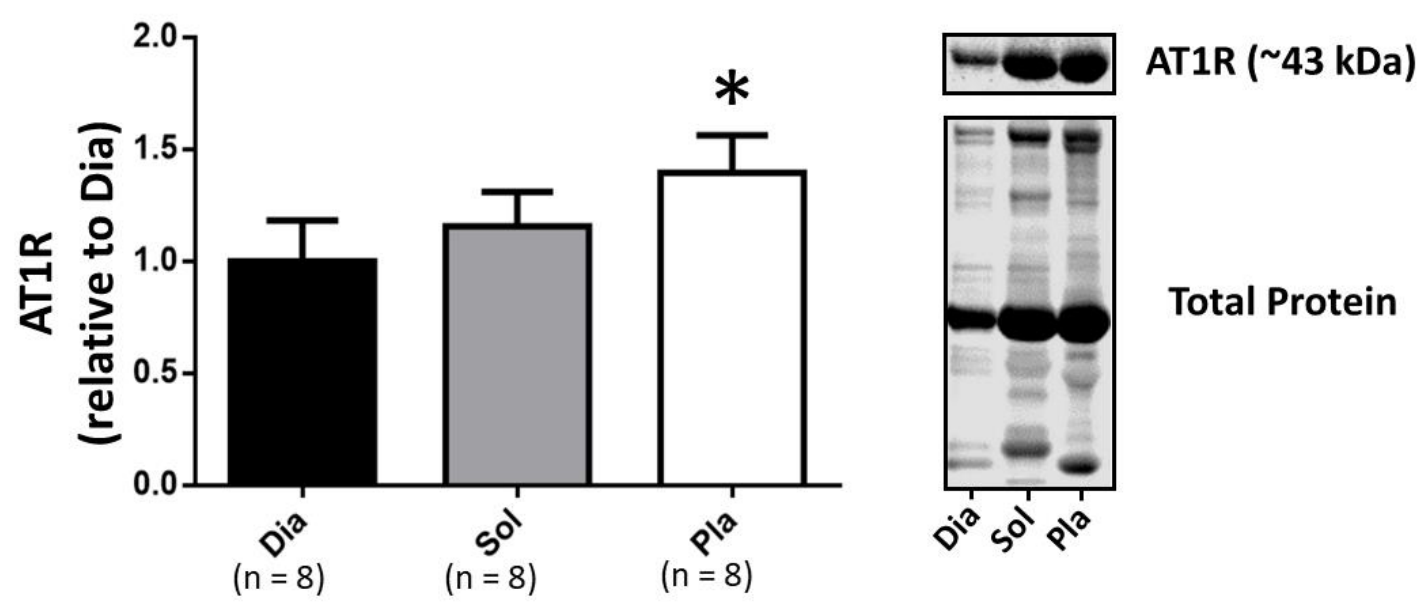

Total Protein

Figure 3. Western blot analysis of isolated single muscle fiber homogenate to quantify the abundance of AT1Rs in the rat diaphragm (Dia), soleus (Sol), and plantaris (Pla) muscles. Data are mean \pm SD.

* significantly different $(p<0.05)$ from diaphragm (Dia) and from soleus (Sol).

\subsection{AT1R mRNA in Rat Skeletal Muscles}

As a final measure of AT1Ra expression in skeletal muscle, we determined the mRNA levels in single muscle fibers isolated from the diaphragm, soleus, and plantaris muscles. These results reveal that AT1Ra mRNA levels were significantly higher in the fast fiber type, plantaris muscle as compared with both the diaphragm and soleus that contained slower muscle fiber types (Figure 4).

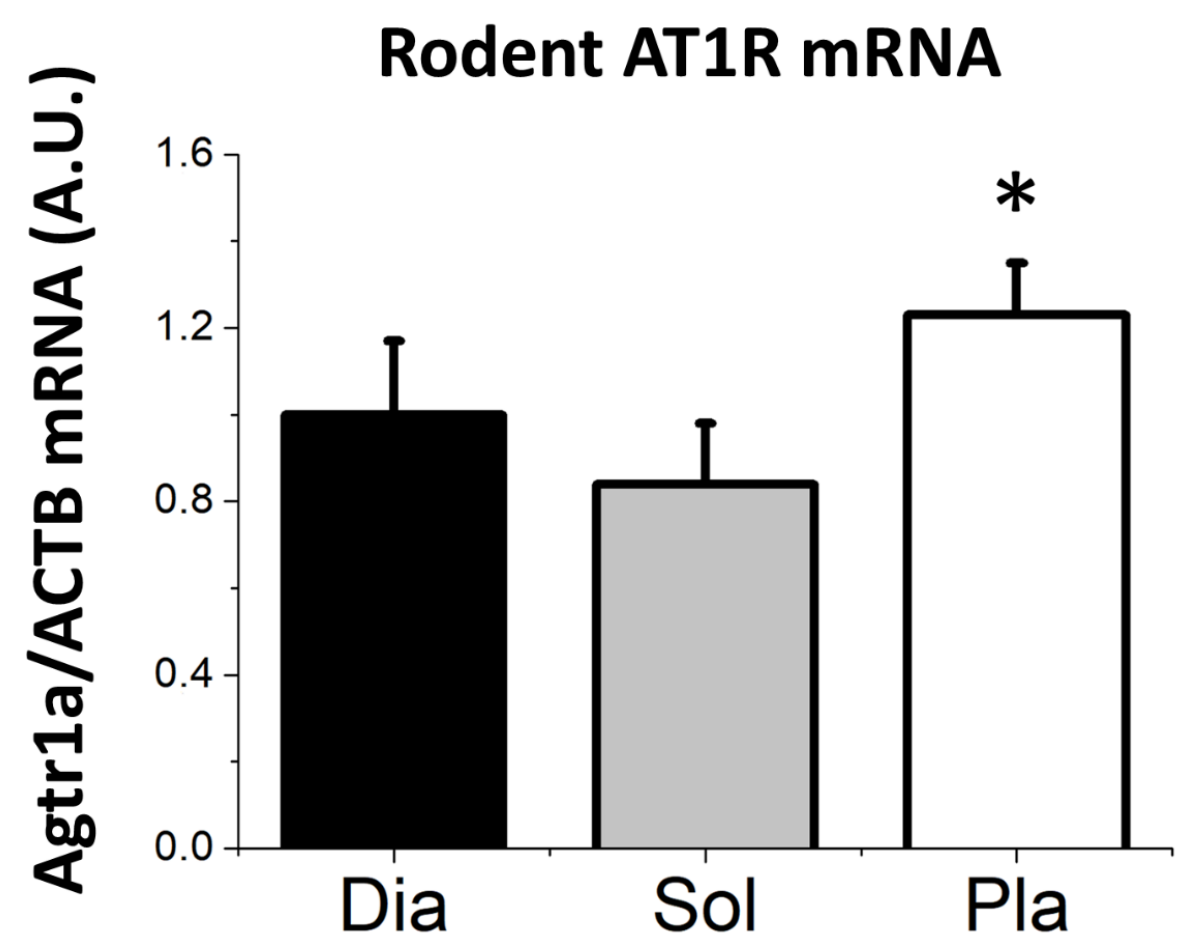

Figure 4. $A T 1 R_{A} m R N A$ from single muscle fibers isolated from the rat diaphragm (Dia), soleus (Sol), and plantaris $(\mathrm{Pla})$ muscles. Data are mean \pm SD. * significantly different $(p<0.05)$ from diaphragm (Dia) and from soleus (Sol). 


\subsection{Both Ligand-Binding and Western Blotting Confirm the Presence of AT1R in Human Diaphragm}

To establish if AT1Rs are expressed in human skeletal muscle, we performed fluorescent ligand binding on isolated single diaphragm fibers and Western blotting using homogenates of single muscle fibers from human diaphragm muscle biopsies. Similar to the rat diaphragm, the human diaphragm is a mixed fiber type muscle containing both slow and fast fiber types. Identical to our findings in the rat, our results confirm the presence of AT1Rs in isolated muscle fibers from the human diaphragm (Figure 5). Specifically, we observed a prominent fluorescent signal from single fibers incubated with TAMRA-AngII (Figure 5A) and the appearance of a single band at the molecular weight ( $43 \mathrm{kDa}$ ) for AT1R in a Western blot (Figure 5B). Collectively, these results from both rat and human muscle tissue provide robust evidence confirming the presence of AT1R protein in skeletal muscle.

A) TAMRA-labeled Angll

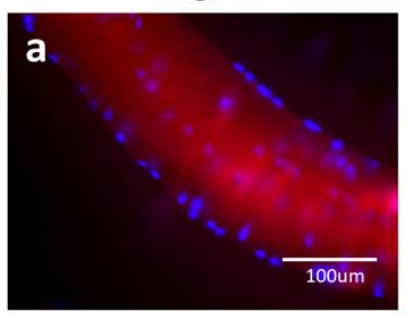

TAMRA-labeled Angll + Losartan

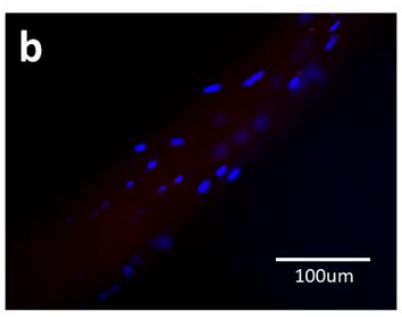

B)

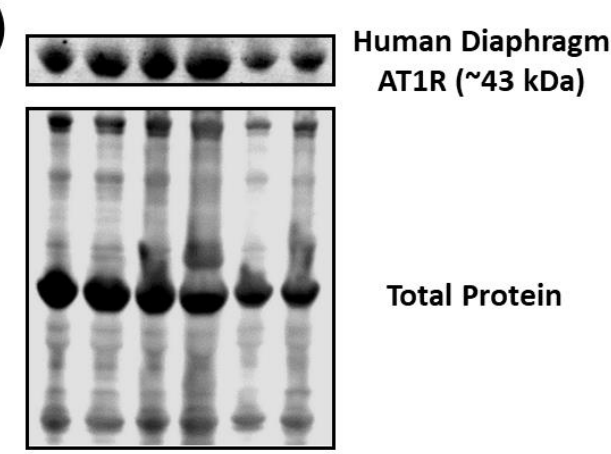

Figure 5. AT1R is present in human diaphragm. Panel (A) illustrates isolated muscle fibers from the human diaphragm incubated with TAMRA-labeled AngII (a) and nonspecific binding after incubation with TAMRA-labeled AngII + $1 \mathrm{mM}$ losartan (b). Skeletal muscle nuclei are identified in blue (DAPI); Panel (B) illustrates a representative Western blot indicating the presence of AT1R protein in the human diaphragm. This immunoblot was generated from a protein homogenate of isolated single muscle fibers from the human diaphragm.

\section{Discussion}

\subsection{Overview of Major Findings}

Using a robust multi-technique approach, our findings support the hypothesis that AT1Rs are expressed in both human and rodent skeletal muscle. Specifically, results from both Western blotting and a fluorescence-based ligand binding assay confirm that AT1Rs are present in both human and rat skeletal muscles. In addition, the presence of AT1R mRNA in rat skeletal muscles provides additional support for this conclusion. These important results provide the first evidence that AT1Rs are expressed in human skeletal muscle. Moreover, our data provide the first robust evidence that AT1Rs exist in rodent skeletal muscles and that AT1Rs are more abundant in fast, type II muscle fibers as compared with slow, type I fibers. Together, these significant discoveries provide the foundation for an improved understanding of the mechanism(s) responsible for AngII-induced skeletal muscle atrophy. A critique of our experimental approach and a discussion of the physiological significance of these findings follows.

\subsection{Critique of Experimental Approach}

Resolving the controversy surrounding the level of AT1R expression in skeletal muscle fibers requires a rigorous experimental approach that avoids the pitfalls associated with previous investigations. In reference to weaknesses of earlier studies, some reports have measured AT1R abundance in only myotubes, whereas others have assessed AT1R levels in whole skeletal muscle homogenate; clearly, both approaches have shortcomings. Furthermore, a major flaw of previous investigations was the use of commercial AT1R antibodies that lacked specificity [20,21]. Indeed, the 
usage of nonspecific antibodies was likely a key contributor to the lack of reproducibility across the skeletal muscle/AT1R literature. A critical analysis of our experimental approach follows.

To avoid the drawback that myotubes may not be representative of adult skeletal muscle fibers, we measured the abundance of AT1Rs within (adult) human and rat skeletal muscle fibers. Furthermore, to circumvent the shortcoming that whole muscle homogenate contains AT1R from vascular tissue, we measured the AT1R abundance within isolated single muscle fibers. As an added precaution, we confirmed that the homogenate from our single muscle fiber samples did not include the vascular biomarker, CD31.

Because many commercially available AT1R antibodies lack specificity [20,21,25], our experiments used the recently generated and highly specific AT1R antibody, D15136-1-5 (see Supplementary Materials, Figure S2). The specificity of this antibody has been validated by Western blotting, demonstrating the presence of a band at the expected molecular weight of AT1Rs (43 kDa) in skeletal muscles from wild type mice; importantly, this band is absent in muscle fibers from AT1R knock-out animals. Additional support for the specificity of the antibody comes from the observation that the density of the $43 \mathrm{kDa}$ band increases in muscles from transgenic animals that overexpress AT1R in skeletal muscle [25].

To compliment the Western blot assessment of AT1R abundance, our experiments also incorporated a fluorescence-based ligand-binding assay to detect both the location and relative abundance of AT1Rs in muscle fibers. Because commercially available AT1R antibodies lack specificity, AngII binding assays are commonly used as the standard method for measuring AT1R abundance in many tissues including the brain, blood vessels, and kidney. However, to our knowledge, the current study is the first application of an AngII binding assay to determine AT1R abundance in skeletal muscle.

Radioligand-binding assays are considered to be the gold standard for quantifying ligand-receptor interactions [31], and while fluorescent-labeled binding assays are less sensitive than radiolabeled methods, fluorescent assays are reliable, safe, and do not produce radioactive waste [32,33]. Moreover, recent improvements in the fluorescence-based ligand binding assay used in this study has reduced the quenching associated with older methods and improved the accuracy of the assay [27,32,33]. Lastly, while the fluorescent-labeled AngII can also bind to Angiotensin II type 2 receptors (AT2Rs), adult skeletal muscle fibers do not express AT2Rs (reviewed in [34]).

As an additional index of AT1R expression in rat skeletal muscle, we measured AT1R mRNA. Only one housekeeping gene, $\beta$-actin, was used for comparisons among tissues. It is possible that relative differences of $\beta$-actin exist between diaphragm, soleus, and plantaris which could contribute to our findings. Nonetheless, our results confirm that AT1R mRNA is present in isolated single muscle fibers from the diaphragm, soleus, and plantaris muscles. Note that AT1R mRNA was not measured in the human muscle samples because of limited tissue availability.

Our experiments determined the AT1R abundance in both respiratory and locomotor muscles. The diaphragm is a mixed fiber type muscle that contains all the muscle fiber types found in both rat and human skeletal muscle [35] and has been studied because activation of the RAS promotes diaphragmatic atrophy during prolonged mechanical ventilation [22]. Therefore, determining if diaphragm fibers express AT1R is important in the development of therapies to prevent ventilator-induced diaphragmatic wasting.

To establish if AT1Rs are differentially expressed in locomotor skeletal muscles that differ in muscle fiber type composition, we studied the rat soleus and plantaris muscles. These muscles were selected because the rat soleus muscle is primarily composed of slow (type I) fibers, whereas the plantaris muscle is dominated by fast (type II) fibers [24]. Collectively, the methods employed within our investigation provide a rigorous approach to determining the presence of AT1Rs in skeletal muscle.

\subsection{Physiological and Clinical Implications of AT1Rs in Skeletal Muscle}

Although these experiments are limited by the absence of a direct measure of AT1R function in skeletal muscle, the confirmation that AT1Rs are expressed in skeletal muscle fibers has important 
implications for future studies seeking to understand the mechanism(s) responsible for AngII-mediated muscle wasting. Explicitly, because of the lack of persuasive evidence that skeletal muscles express AT1R, it has been postulated that AngII-induced muscle atrophy occurs via the indirect effects of AngII acting to increase circulating cortisol or cytokines [10]. However, given the compelling evidence within the current report that AT1Rs are expressed in skeletal muscles, it appears probable that AngII stimulated muscle atrophy can also occur by activation of AT1Rs on the sarcolemma. The link between AT1R activation and muscle atrophy is likely the AT1R-provoked activation of NOX2 and the subsequent production of reactive oxygen species (ROS) [3]. Indeed, it is established that oxidative stress promotes skeletal muscle atrophy by both accelerated proteolysis and depressed protein synthesis [12]. Evidence that AngII-mediated muscle atrophy occurs via NOX2-induced oxidative stress is supported by the observation that knockout mice lacking p47 (phox), a required subunit for NOX2 activation, are protected against AngII-induced muscle wasting [36].

Interestingly, emerging evidence reveals that, independent of elevated circulating AngII, activation of AT1Rs contribute to the diaphragmatic atrophy that occurs during prolonged mechanical ventilation (MV) [22]. Although MV is a life-saving intervention for patients in respiratory failure, an unintended consequence of prolonged MV is the rapid development of diaphragmatic atrophy [37]. Preclinical studies have demonstrated that pharmacological blockade of AT1Rs protects against ventilator-induced diaphragmatic atrophy [22]. In contrast, prevention of the increase in circulating AngII (via pharmacological inhibition of angiotensin converting enzyme) does not avert MV-induced diaphragmatic atrophy [22]. Moreover, plasma levels of cortisol, IL-6, and SAA do not increase during prolonged MV. Therefore, these results confirm that activation of AT1Rs is required for MV-induced diaphragmatic atrophy and that indirect RAS signaling does not contribute to ventilator-induced diaphragmatic atrophy. In this regard, evidence shows that independent of ligand binding, AT1R activation can occur in response to mechanical activation of the receptor [38]. Hence, it is feasible that diaphragmatic AT1Rs are activated during MV by mechanical forces applied to the sarcolemma [38]. Specifically, during MV, diaphragm muscle fibers undergo repetitive, passive length changes (shortening and lengthening cycles); the force of these passive length changes is imposed by transverse forces from the MV-induced (positive pressure) inflation of the lung rather than the axial forces that occur during normal diaphragm contractions [39]. Moreover, for a given change in lung volume, diaphragm fibers shorten more during MV than during spontaneous breathing $[3,40]$. Hence, it is predicted that the transverse tension on the sarcolemma of diaphragm fibers is greater during MV as compared with spontaneous breathing. If this is the case, this MV-induced increase in membrane tension could be responsible for the activation of AT1Rs in diaphragm fibers [3,41,42].

While preclinical studies provided the first proof that prolonged MV results in rapid diaphragmatic atrophy, it is now established that MV-induced diaphragmatic atrophy also occurs in humans [43-45]. MV-induced diaphragmatic atrophy is a serious clinical problem because diaphragm weakness is a major risk factor for problems in weaning patients from the ventilator [46]. Therefore, our discovery that AT1Rs are expressed in human diaphragm fibers is important and provides key insights into a potential biological target for future therapies to prevent MV-induced diaphragmatic atrophy.

In addition to confirming that skeletal muscles express AT1Rs, our results also provide the first evidence that AT1R abundance is higher in skeletal muscles as composed with that of fast-twitch muscle fibers (i.e., plantaris) as compared with muscles comprised of slow fibers (i.e., soleus) and muscles containing a combination of both slow and fast fibers (i.e., diaphragm) [24]. The discovery that AT1Rs are more abundant in fast muscle fibers provides biological insight into a potential mechanism to explain why diseases associated with high circulating levels of AngII (i.e., chronic kidney disease, heart failure, etc.) promote greater atrophy in locomotor muscles comprised of primarily type II fibers [47-49]. In a related finding, evidence indicated that NOX2 activity was markedly increased in the plantaris muscle of rodents in heart failure [50]. This observation raises the intriguing question of whether this heart failure-induced activation of NOX2 was mechanistically linked to the high expression of AT1Rs in the plantaris muscle. Notably, further experiments are required in order to 
determine if higher AT1R abundance in plantaris translates to increased NOX2 signaling. Indeed, the discovery that AT1R expression is greater in fast muscle fibers should stimulate future research into the mechanisms responsible for the differential rate of skeletal muscle atrophy in diseases associated with high plasma levels of AngII.

\section{Conclusions}

Our results provide the first robust proof that both human and rodent skeletal muscles express AT1Rs. Importantly, our data also deliver the first evidence that AT1R abundance is greater in muscles with a high percentage of type II (fast) fibers as compared with muscles with a high composition of type I (slow) fibers. Historically, physiologists have believed that the primary role of the RAS is to regulate fluid, electrolyte, and blood pressure homeostasis. However, our findings that AT1Rs exist in skeletal muscle raise important questions that should stimulate future research on the physiological function of AT1Rs in both healthy skeletal muscle and in muscles undergoing atrophy in response to both disease and muscle inactivity (e.g., heart failure, kidney disease, or prolonged mechanical ventilation). Lastly, the discovery that AT1Rs exist in the human diaphragm is an important and novel finding that has significant potential to contribute to future research into the involvement of AT1Rs in ventilator-induced diaphragmatic atrophy and the development of protective therapies.

Supplementary Materials: The following are available online at http://www.mdpi.com/2073-4409/9/7/1688/s1, Figure S1: In vitro localization of AT1R in smooth muscle of rat aorta (vasculature), renal cortex and plantaris muscle, Figure S2: Full length images of western blots for AT1R and total protein in rodent and human muscle.

Author Contributions: Conceptualization, H.H. and S.P.; Data curation, R.D., H.H., T.Y., and M.O.; Formal analysis, R.D. and H.H.; Funding acquisition, S.P.; Investigation, R.D., H.H., T.Y., M.O., and B.N.; Methodology, R.D., H.H., T.Y., and S.P.; Project administration, R.D., H.H., and S.P.; Resources, S.L. and S.P.; Supervision, R.D., H.H., and S.P.; Validation, R.D., H.H., and S.P.; Visualization, R.D. and H.H.; Writing-original draft, R.D., H.H., and S.P.; Writing-review and editing, R.D., H.H., T.Y., M.O., and S.P. All authors have read and agreed to the published version of the manuscript.

Funding: This work was supported by a grant from the National Institutes of Health (R21AR063956 to S.K.P.).

Acknowledgments: This work was supported by a grant from the National Institutes of Health (R21AR063956 to S.K.P.). Rafael Deminice was supported from Conselho Nacional de Desenvolvimento Científico e Tecnológico-CNPq, Brazil \# 206444/2017-6.

Conflicts of Interest: The authors declare no conflict of interest.

\section{References}

1. Cabello-Verrugio, C.; Cordova, G.; Salas, J.D. Angiotensin II: Role in skeletal muscle atrophy. Curr. Protein Pept. Sci. 2012, 13, 560-569. [CrossRef]

2. Cabello-Verrugio, C.; Morales, M.G.; Rivera, J.C.; Cabrera, D.; Simon, F. Renin-angiotensin system. An old player with novel functions in skeletal muscle. Med. Res. Rev. 2015, 35, 437-463. [CrossRef] [PubMed]

3. Powers, S.K.; Morton, A.B.; Hyatt, H.; Hinkley, M.J. The Renin-Angiotensin System and Skeletal Muscle. Exerc. Sport Sci. Rev. 2018, 46, 205-214. [CrossRef] [PubMed]

4. Yoshida, T.; Tabony, A.M.; Galvez, S.; Mitch, W.E.; Higashi, Y.; Sukhanov, S.; Delafontaine, P. Molecular mechanisms and signaling pathways of angiotensin II-induced muscle wasting: Potential therapeutic targets for cardiac cachexia. Int. J. Biochem. Cell Biol. 2013, 45, 2322-2332. [CrossRef]

5. Dirks, M.L.; Wall, B.T.; van de Valk, B.; Holloway, T.M.; Holloway, G.P.; Chabowski, A.; Goossens, G.H.; van Loon, L.J. One Week of Bed Rest Leads to Substantial Muscle Atrophy and Induces Whole-Body Insulin Resistance in the Absence of Skeletal Muscle Lipid Accumulation. Diabetes 2016, 65, 2862-2875. [CrossRef] [PubMed]

6. Haruna, Y.; Bonde-Petersen, F.; Takenaka, K.; Suzuki, Y.; Kawakubo, K.; Gunji, A. Effects of the renin-angiotensin-aldosterone system on the cardiovascular system during 20-days bed rest. J. Gravit. Physiol. 1997, 4, S62-S68. [PubMed]

7. Suzuki, T.; Palus, S.; Springer, J. Skeletal muscle wasting in chronic heart failure. ESC Heart Fail. 2018, 5, 1099-1107. [CrossRef] 
8. Van de Wal, R.M.; Plokker, H.W.; Lok, D.J.; Boomsma, F.; van der Horst, F.A.; van Veldhuisen, D.J.; van Gilst, W.H.; Voors, A.A. Determinants of increased angiotensin II levels in severe chronic heart failure patients despite ACE inhibition. Int. J. Cardiol. 2006, 106, 367-372. [CrossRef]

9. Wang, X.H.; Mitch, W.E. Mechanisms of muscle wasting in chronic kidney disease. Nat. Rev. Nephrol. 2014, 10, 504-516. [CrossRef]

10. Zhang, L.; Du, J.; Hu, Z.; Han, G.; Delafontaine, P.; Garcia, G.; Mitch, W.E. IL-6 and serum amyloid A synergy mediates angiotensin II-induced muscle wasting. J. Am. Soc. Nephrol. 2009, 20, 604-612. [CrossRef]

11. Schakman, O.; Kalista, S.; Barbe, C.; Loumaye, A.; Thissen, J.P. Glucocorticoid-induced skeletal muscle atrophy. Int. J. Biochem. Cell Biol. 2013, 45, 2163-2172. [CrossRef] [PubMed]

12. Powers, S.K.; Ozdemir, M.; Hyatt, H. Redox Control of Proteolysis during Inactivity-Induced Skeletal Muscle Atrophy. Antioxid. Redox Signal. 2020. [CrossRef]

13. Paxton, W.G.; Runge, M.; Horaist, C.; Cohen, C.; Alexander, R.W.; Bernstein, K.E. Immunohistochemical localization of rat angiotensin II AT1 receptor. Am. J. Physiol. 1993, 264, F989-F995. [CrossRef]

14. Cabello-Verrugio, C.; Acuna, M.J.; Morales, M.G.; Becerra, A.; Simon, F.; Brandan, E. Fibrotic response induced by angiotensin-II requires $\mathrm{NAD}(\mathrm{P}) \mathrm{H}$ oxidase-induced reactive oxygen species (ROS) in skeletal muscle cells. Biochem. Biophys. Res. Commun. 2011, 410, 665-670. [CrossRef]

15. Cabello-Verrugio, C.; Morales, M.G.; Cabrera, D.; Vio, C.P.; Brandan, E. Angiotensin II receptor type 1 blockade decreases CTGF/CCN2-mediated damage and fibrosis in normal and dystrophic skeletal muscles. J. Cell. Mol. Med. 2012, 16, 752-764. [CrossRef] [PubMed]

16. Morales, M.G.; Vazquez, Y.; Acuna, M.J.; Rivera, J.C.; Simon, F.; Salas, J.D.; Alvarez Ruf, J.; Brandan, E.; Cabello-Verrugio, C. Angiotensin II-induced pro-fibrotic effects require p38MAPK activity and transforming growth factor beta 1 expression in skeletal muscle cells. Int. J. Biochem. Cell Biol. 2012, 44, 1993-2002. [CrossRef]

17. Russell, S.T.; Sanders, P.M.; Tisdale, M.J. Angiotensin II directly inhibits protein synthesis in murine myotubes. Cancer Lett. 2006, 231, 290-294. [CrossRef]

18. Sanders, P.M.; Russell, S.T.; Tisdale, M.J. Angiotensin II directly induces muscle protein catabolism through the ubiquitin-proteasome proteolytic pathway and may play a role in cancer cachexia. Br. J. Cancer 2005, 93, 425-434. [CrossRef] [PubMed]

19. Sun, G.; Haginoya, K.; Dai, H.; Chiba, Y.; Uematsu, M.; Hino-Fukuyo, N.; Onuma, A.; Iinuma, K.; Tsuchiya, S. Intramuscular renin-angiotensin system is activated in human muscular dystrophy. J. Neurol. Sci. 2009, 280, 40-48. [CrossRef] [PubMed]

20. Benicky, J.; Hafko, R.; Sanchez-Lemus, E.; Aguilera, G.; Saavedra, J.M. Six commercially available angiotensin II AT1 receptor antibodies are non-specific. Cell. Mol. Neurobiol. 2012, 32, 1353-1365. [CrossRef]

21. Herrera, M.; Sparks, M.A.; Alfonso-Pecchio, A.R.; Harrison-Bernard, L.M.; Coffman, T.M. Lack of specificity of commercial antibodies leads to misidentification of angiotensin type 1 receptor protein. Hypertension 2013, 61, 253-258. [CrossRef]

22. Kwon, O.S.; Smuder, A.J.; Wiggs, M.P.; Hall, S.E.; Sollanek, K.J.; Morton, A.B.; Talbert, E.E.; Toklu, H.Z.; Tumer, N.; Powers, S.K. AT1 receptor blocker losartan protects against mechanical ventilation-induced diaphragmatic dysfunction. J. Appl. Physiol. 2015, 119, 1033-1041. [CrossRef]

23. Zambelli, V.; Sigurta, A.; Rizzi, L.; Zucca, L.; Delvecchio, P.; Bresciani, E.; Torsello, A.; Bellani, G. Angiotensin-(1-7) exerts a protective action in a rat model of ventilator-induced diaphragmatic dysfunction. Intensive Care Med. Exp. 2019, 7, 8. [CrossRef]

24. Delp, M.D.; Duan, C. Composition and size of type I, IIA, IID/X, and IIB fibers and citrate synthase activity of rat muscle. J. Appl. Physiol. 1996, 80, 261-270. [CrossRef]

25. Murphy, K.T.; Hossain, M.I.; Swiderski, K.; Chee, A.; Naim, T.; Trieu, J.; Haynes, V.; Read, S.J.; Stapleton, D.I.; Judge, S.M.; et al. Mas Receptor Activation Slows Tumor Growth and Attenuates Muscle Wasting in Cancer. Cancer Res. 2019, 79, 706-719. [CrossRef]

26. Kirshner, Z.Z.; Gibbs, R.B. Use of the REVERT((R)) total protein stain as a loading control demonstrates significant benefits over the use of housekeeping proteins when analyzing brain homogenates by Western blot: An analysis of samples representing different gonadal hormone states. Mol. Cell. Endocrinol. 2018, 473, 156-165. [CrossRef] [PubMed] 
27. Bragina, M.E.; Stergiopulos, N.; Fraga-Silva, R. Fluorescence-based binding assay for screening ligands of angiotensin receptors. In The Renin-Angiotensin-Aldosterone System: Methods and Protocols, Methods in Molecular Biology; Thacher, S., Ed.; Human Press: New York, NY, USA, 2017; Volume 1614, pp. 165-174.

28. Falcon, B.L.; Stewart, J.M.; Bourassa, E.; Katovich, M.J.; Walter, G.; Speth, R.C.; Sumners, C.; Raizada, M.K. Angiotensin II type 2 receptor gene transfer elicits cardioprotective effects in an angiotensin II infusion rat model of hypertension. Physiol. Genom. 2004, 19, 255-261. [CrossRef]

29. Phansalkar, N.A.S.; Joshi, M. Adaptive local thresholding for detection of nuclei in diversity stained cytology images. In Proceedings of the 2011 International Conference on Communications and Signal Processing, Calicut, India, 10-12 February 2012; pp. 218-220. [CrossRef]

30. Yoshida, T.; Huq, T.S.; Delafontaine, P. Angiotensin type 2 receptor signaling in satellite cells potentiates skeletal muscle regeneration. J. Biol. Chem. 2014, 289, 26239-26248. [CrossRef]

31. Dong, C.; Liu, Z.; Wang, F. Radioligand saturation binding for quantitative analysis of ligand-receptor interactions. Biophys. Rep. 2015, 1, 148-155. [CrossRef]

32. Breen, C.J.; Raverdeau, M.; Voorheis, H.P. Development of a quantitative fluorescence-based ligand-binding assay. Sci. Rep. 2016, 6, 25769. [CrossRef]

33. Martin, R.P.; Filippelli-Silva, R.; Rodrigues, E.S.; Nakaie, C.R.; Shimuta, S.I. A fluorimetric binding assay for angiotensin II and kinin receptors. J. Pharmacol. Toxicol. Methods 2016, 79, 55-59. [CrossRef] [PubMed]

34. De Gasparo, M.; Catt, K.J.; Inagami, T.; Wright, J.W.; Unger, T. International union of pharmacology. XXIII. The angiotensin II receptors. Pharm. Rev. 2000, 52, 415-472. [PubMed]

35. Tikunov, B.A.; Mancini, D.; Levine, S. Changes in myofibrillar protein composition of human diaphragm elicited by congestive heart failure. J. Mol. Cell. Cardiol. 1996, 28, 2537-2541. [CrossRef]

36. Semprun-Prieto, L.C.; Sukhanov, S.; Yoshida, T.; Rezk, B.M.; Gonzalez-Villalobos, R.A.; Vaughn, C.; Michael Tabony, A.; Delafontaine, P. Angiotensin II induced catabolic effect and muscle atrophy are redox dependent. Biochem. Biophys. Res. Commun. 2011, 409, 217-221. [CrossRef]

37. Powers, S.K.; Wiggs, M.P.; Sollanek, K.J.; Smuder, A.J. Ventilator-induced diaphragm dysfunction: Cause and effect. Am. J. Physiol. Regul. Integr. Comp. Physiol. 2013, 305, R464-R477. [CrossRef]

38. Yasuda, N.; Miura, S.; Akazawa, H.; Tanaka, T.; Qin, Y.; Kiya, Y.; Imaizumi, S.; Fujino, M.; Ito, K.; Zou, Y.; et al. Conformational switch of angiotensin II type 1 receptor underlying mechanical stress-induced activation. EMBO Rep. 2008, 9, 179-186. [CrossRef] [PubMed]

39. Kumar, A.; Chaudhry, I.; Reid, M.B.; Boriek, A.M. Distinct signaling pathways are activated in response to mechanical stress applied axially and transversely to skeletal muscle fibers. J. Biol. Chem. 2002, 277, 46493-46503. [CrossRef]

40. Newman, S.; Road, J.; Bellemare, F.; Clozel, J.P.; Lavigne, C.M.; Grassino, A. Respiratory muscle length measured by sonomicrometry. J. Appl. Physiol. Respir. Environ. Exerc. Physiol. 1984, 56, 753-764. [CrossRef]

41. Boriek, A.M.; Hwang, W.; Trinh, L.; Rodarte, J.R. Shape and tension distribution of the active canine diaphragm. Am. J. Physiol. Regul. Integr. Comp. Physiol. 2005, 288, R1021-R1027. [CrossRef]

42. Boriek, A.M.; Rodarte, J.R.; Reid, M.B. Shape and tension distribution of the passive rat diaphragm. Am. J. Physiol. Regul. Integr. Comp. Physiol. 2001, 280, R33-R41. [CrossRef]

43. Hussain, S.N.; Mofarrahi, M.; Sigala, I.; Kim, H.C.; Vassilakopoulos, T.; Maltais, F.; Bellenis, I.; Chaturvedi, R.; Gottfried, S.B.; Metrakos, P.; et al. Mechanical ventilation-induced diaphragm disuse in humans triggers autophagy. Am. J. Respir. Crit. Care Med. 2010, 182, 1377-1386. [CrossRef] [PubMed]

44. Jaber, S.; Petrof, B.J.; Jung, B.; Chanques, G.; Berthet, J.P.; Rabuel, C.; Bouyabrine, H.; Courouble, P.; Koechlin-Ramonatxo, C.; Sebbane, M.; et al. Rapidly progressive diaphragmatic weakness and injury during mechanical ventilation in humans. Am. J. Respir. Crit. Care Med. 2011, 183, 364-371. [CrossRef] [PubMed]

45. Levine, S.; Nguyen, T.; Taylor, N.; Friscia, M.E.; Budak, M.T.; Rothenberg, P.; Zhu, J.; Sachdeva, R.; Sonnad, S.; Kaiser, L.R.; et al. Rapid disuse atrophy of diaphragm fibers in mechanically ventilated humans. N. Engl. J. Med. 2008, 358, 1327-1335. [CrossRef]

46. Sellares, J.; Ferrer, M.; Cano, E.; Loureiro, H.; Valencia, M.; Torres, A. Predictors of prolonged weaning and survival during ventilator weaning in a respiratory ICU. Intensive Care Med. 2011, 37, 775-784. [CrossRef]

47. Carvalho, R.F.; Castan, E.P.; Coelho, C.A.; Lopes, F.S.; Almeida, F.L.; Michelin, A.; de Souza, R.W.; Araujo, J.P., Jr.; Cicogna, A.C.; Dal Pai-Silva, M. Heart failure increases atrogin-1 and MuRF1 gene expression in skeletal muscle with fiber type-specific atrophy. J. Mol. Histol. 2010, 41, 81-87. [CrossRef] [PubMed] 
48. Flisinski, M.; Brymora, A.; Elminowska-Wenda, G.; Bogucka, J.; Walasik, K.; Stefanska, A.; Strozecki, P.; Manitius, J. Morphometric analysis of muscle fibre types in rat locomotor and postural skeletal muscles in different stages of chronic kidney disease. J. Physiol. Pharm. 2014, 65, 567-576.

49. Wang, Y.; Pessin, J.E. Mechanisms for fiber-type specificity of skeletal muscle atrophy. Curr. Opin. Clin. Nutr. Metab. Care 2013, 16, 243-250. [CrossRef] [PubMed]

50. Bechara, L.R.; Moreira, J.B.; Jannig, P.R.; Voltarelli, V.A.; Dourado, P.M.; Vasconcelos, A.R.; Scavone, C.; Ramires, P.R.; Brum, P.C. NADPH oxidase hyperactivity induces plantaris atrophy in heart failure rats. Int. J. Cardiol. 2014, 175, 499-507. [CrossRef] [PubMed]

(C) 2020 by the authors. Licensee MDPI, Basel, Switzerland. This article is an open access article distributed under the terms and conditions of the Creative Commons Attribution (CC BY) license (http://creativecommons.org/licenses/by/4.0/). 